\title{
DR-29. PREPARATION OF INDOLE-CONTAINING 3-(2-PYRIDYL)-1,2,4-TRIAZINES AS TRYPTAMINE DERIVATIVES
}

M. I. Savchuk ${ }^{1}$, D. S. Kopchuk ${ }^{1,2}$, A. P. Krinochkin ${ }^{1,2}$, I. S. Kovalev ${ }^{1}$, G. V. Zyryanov ${ }^{1,2}$, V. L. Rusinov ${ }^{1,2}$, O. N. Chupakhin ${ }^{1,2}$

${ }^{1}$ Ural Federal University of the first President of Russia B. N. Yeltsin, Mira St., 19, Yekaterinburg, 620002, Russia

${ }^{2}$ I. Ya. Postovsky Institute of Organic Synthesis UB RAS,

S. Kovalevskoy/Akademicheskaya St., 20/22, Yekaterinburg, 620990, Russia

E-mail: savchuk.chuk@yandex.ru

Indole derivatives, including 1,2,4-triazine containing ones, are of interest from the point of view of their biological activity. In this publication, we propose a method for obtaining a Schiff base, comprising indole and 3-(2-pyridyl)-1,2,4-triazine fragments.

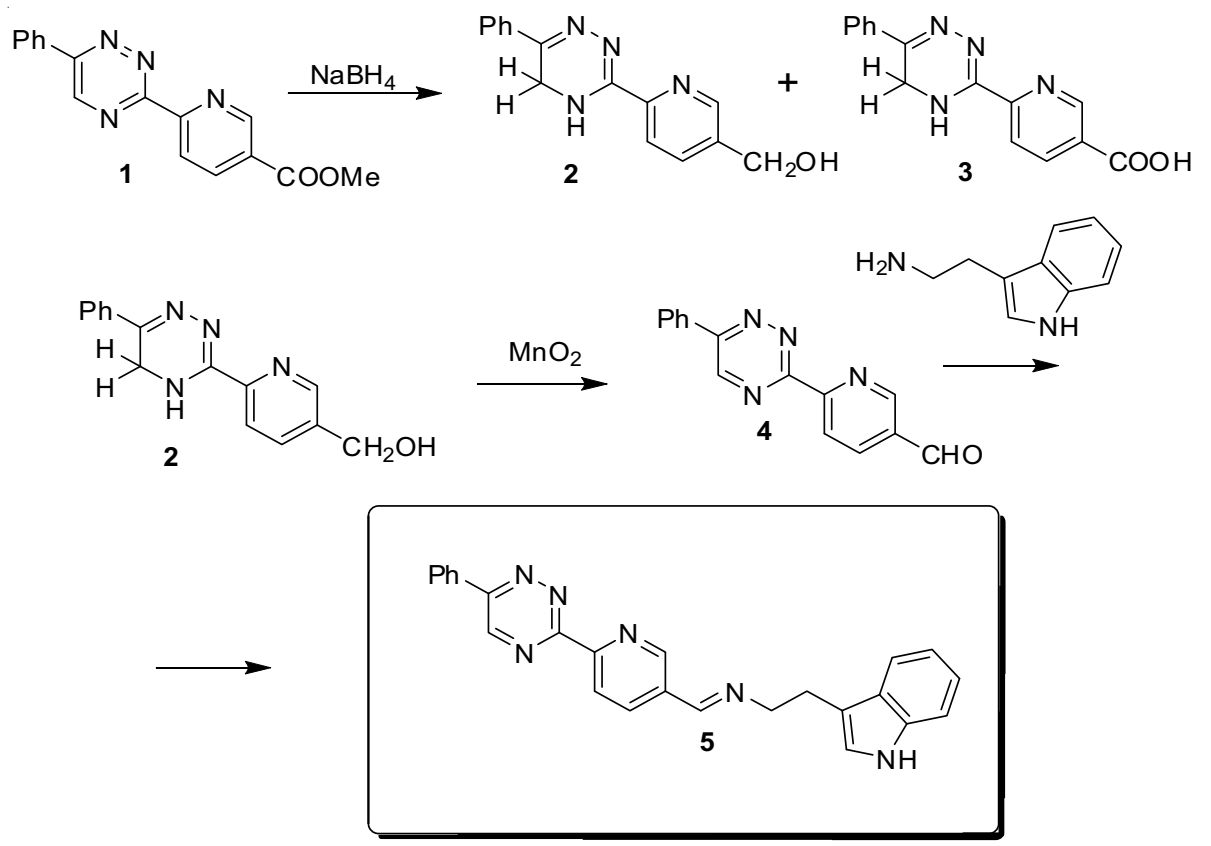

This work was supported by the Russian Science Foundation (Ref. № 18-73-10119). 